\title{
Aspectos do desenvolvimento do cultivo do bijupirá Rachycentron canadum no Brasil e no mundo
}

\author{
Aspects of development of bijupirá Rachycentron canadum in Brazil and in the \\ world
}

IGARASHI, Marco Antônio. Doutor/Tecnólogo em Aquicultura

Secretaria Especial de Aquicultura e Pesca da Presidência da República - DF, Ministério da Pesca e Aquicultura/Paraná. Av. do Café, 543, Anexo A - Londrina - Paraná - Brasil. CEP: 86038-000/ Telefone: ((43) 33257649/ E-mail: igarashi@ufc.br

\section{RESUMO}

O objetivo do presente artigo de revisão é realizar uma sinopse com uma visão geral da situação atual da criação de bijupirá, com possíveis adaptações e inovações que podem ser úteis ao desenvolvimento da metodologia de cultivo comercial de bijupirá. O bijupirá Rachycentron canadum, é um peixe marinho amplamente distribuído nas águas do Indo-Pacífico até o sudeste do Oceano Atlântico com potencial emergente para a maricultura, devido ao seu alto valor no mercado nacional e internacional, capacidade de desovar em tanques, taxa de crescimento atingindo mais de $6 \mathrm{~kg} / \mathrm{ano}$ e alta qualidade dos filés. Este artigo apresenta uma análise do cultivo de bijupirá e proverá uma revisão do cultivo focalizando principalmente a reprodução, produção de larvas, formas jovens, engorda e as iniciativas recentes de pesquisa. Esta sinopse demonstra que os juvenis podem ser cultivados sob regime de confinamento e se adaptam bem as condições artificiais com alimentação e possui características que fazem do bijupirá um peixe marinho provavelmente apropriado para o cultivo comercial no Brasil.

Palavras-chave: Cultivo de bijupirá, marinho, produção comercial.

\section{ABSTRACT}

The objective of this review article is to present a synopsis with an overview of the current situation of culture of Cobia, with possible adaptations and innovations that may be useful to the development of cobia commercial culture methodology. The cobia Rachycentron canadum, is a marine fish widely distributed from the Indo-Pacific waters to the southern Atlantic Ocean with emerging global potential for mariculture, due to its high market value in both domestic and international markets, capacity for natural and induced tank spawning, growth rates in excess of 6 $\mathrm{kg} /$ year and highquality fillet. This review article presents an analysis of cobia culture and will provide an overview of production mainly focus on larval rearing, juvenile, grow-out and ongoing research initiatives. More research is needed before commercial-scale culture. The review showed that the cobia juvenile can be held in communal culture systems, adapt well to the artificial conditions with feeding and growth characteristics that make cobia probably a suitable marine fish for commercial culture in Brazil.

keywords: Cobia culture, marine, commercial production. 
IGARASHI, M.A..

Aspectos do desenvolvimento do cultivo do bijupirá Rachycentron canadum no Brasil e no mundo

\section{Introdução}

O bijupirá (Rachycentron canadum) é forte candidato para piscicultura marinha no Brasil (SHIMADA, 2015). O bijupirá $R$. canadum, tem sido pesquisado em vários aspectos visando seu cultivo comercial no Brasil. Possui rápida taxa de crescimento, baixa mortalidade, alta taxa de conversão alimentar (CALIXTO et al., 2017), utilização efetiva de ração, alto valor de mercado (LIAO et al., 2004; ZHOU et al., 2006; BENETTI et al., 2010), boa qualidade da carne, adaptação e tolerância a variações em temperatura e salinidade (ESTRADA et al., 2016). A escolha do bijupirá como alvo da piscicultura marinha se deve principalmente a sua alta taxa de crescimento (DOMINGUES, 2012) pode alcançar $10 \mathrm{~kg}$ em 1 ano. Devido a estes atributos, esta espécie tem sido amplamente utilizada na aquicultura em alguns países da Ásia e região do Pacífico (ZHOU et al., 2006; GOPAKUMAR et al., 2011; SAKTHIVEL et a., 2012; SANTOS et al., 2016). Nesse contexto a China continental (pelo menos Hainan e Fujian) também possui produção comercial; Guangdong reporta um volume menor em sua produção, mas significativo (HUANG et al., 2011). O Vietnã é o terceiro maior produtor e a produção ou pesquisa de bijupirá também é relatada nos EUA, Bahamas, Belize, República Dominicana, México, Brasil, Porto Rico, Filipinas (FAO, 2017), Equador (KWOK, 2016), Índia (GOPAKUMAR et al., 2011; SAKTHIVEL et a., 2012; PHILIPOSE et al., 2013 ), Irã (HARLIOGLU; FARHADI 2017) além da Austrália (BENETTI et al., 2010). As estatísticas de 2013 indicaram uma produção mundial de mais de 43.000 toneladas métricas, equivalente a US $\$ 74,7$ milhões, com potencial para crescer (RODRIGUEZ-ESTRADA et al., 2015); em 2016 a produção mundial de bijupirá, foi estimado em 43.107 toneladas (FAO, 2018), com maior quantidade originado de tanques -rede implantado em áreas costeiras protegidas da China, Taiwan e Vietnam (NHU et al., 2011; FAO, 2018).

O cultivo de bijupirá foi iniciado em Taiwan em 1995 (LIAO, 2004) e no Brasil em cativeiro foi iniciada em 2006 (CAVALLI et al., 2011). No Brasil foram realizadas experimentos em duas fazendas de cultivo longe da costa de Recife, e em pequena escala de cultivo de bijupirá próximos a costa do litoral do Rio de Janeiro e em São Paulo (BEZERRA et al., 2016). No entanto o ciclo produtivo do bijupirá ainda está em estudo, porém o método de criação mais bem estabelecido é o do Taiwan, por ser esse o país onde esta atividade está desenvolvida por um maior período de tempo (BOTELHO, 2017). O cultivo de peixes marinhos está em seus primeiros passos no Brasil (LIMA et al., 2018). $O$ bijupirá ( $R$. canadum) vem se destacando nos últimos anos na maricultura brasileira, sendo estudado sob diferentes aspectos com vistas à produção comercial no Brasil (COLLAÇO et al., 2015).

A piscicultura marinha brasileira ainda é incipiente e apesar de poder ser uma atividade economicamente viável, a demanda por insumos e equipamentos exigidos para este tipo de cultivo ainda é baixa o que dificulta o desenvolvimento e crescimento do mercado brasileiro que envolve o cultivo de bijupirá e de peixes marinhos em geral (ARGENTIM, 2016). Neste processo, o conhecimento a respeito da espécie e da tecnologia de criação em outras partes do mundo e sua adaptação às condições brasileiras pode contribuir para minimizar o tempo para se alcançar o sucesso na atividade (HAMILTON et al., 2013). A indústria pesqueira também acredita na maricultura como substituto em potencial de seus lucros (COLLAÇO et al., 2015). Os maiores problemas 
IGARASHI, M.A..

Aspectos do desenvolvimento do cultivo do bijupirá Rachycentron canadum no Brasil e no mundo

encontrados ao longo dos anos de criação se referem principalmente à alimentação, patógenos e necessidade de mais pesquisas para um melhor conhecimento da espécie (BOTELHO, 2017). Portanto o objetivo do presente artigo de revisão é realizar uma sinopse com uma visão geral do estado atual da criação de bijupirá, com as principais informações e descobertas recentes na pesquisa, debates atuais, ideias de onde as possíveis adaptações e inovações que podem ser úteis ao desenvolvimento da metodologia de cultivo comercial de bijupirá. Porém é necessário um maior número de pesquisas para estabelecer uma metodologia de cultivo em grande escala do bijupirá $R$. canadum no Brasil.

\section{Fundamentação teórica}

\section{A espécie}

O bijupirá (Figura 1) é conhecido internacionalmente por uma variedade de nomes, incluindo cobia, mafou, ling, lemon fish, black salmon, black kingfish, sergeant fish, runner e crabeater (SILVA, 2016). O bijupirá R. canadum (Linnaeus,1766) é um peixe grande, excelente para o desenvolvimento comercial devido ao alto desempenho na aquicultura (CALIXTO et al., 2017). Esta espécie é considerada um carnívoro voraz cujas principais presas são caranguejos, invertebrados bentônicos e peixes (COLLETTE, 1999).

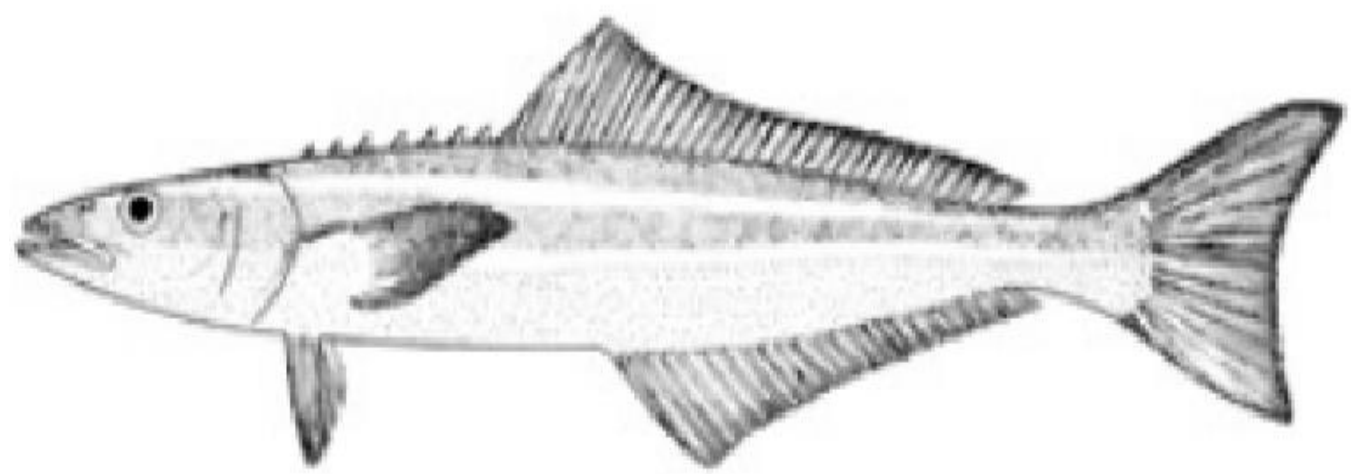

Figura 1. The cobia Rachycentron canadum (FAO, 2007)

O bijupirá $R$. canadum é um peixe marinho nativo do Brasil, nerítico e comportamento migratório e é amplamente distribuído em águas tropicais e subtropicais de todos os oceanos, com exceção do Pacífico Central e Oriental (FAGUNDES et al., 2018). O bijupirá $R$. canadum (Linnaeus, 1766) é a única espécie conhecida da família Rachycentridae. $R$. canadum é um pelágico, espécie altamente migratória, encontradas até profundidades de $1200 \mathrm{~m}$ que também habitam recifes e estuários de corais e rochas (CASTELLANOS-GALINDO et al., 2016). Miao et al. (2009) afirmaram que a temperatura ideal para a espécie está entre $22^{\circ} \mathrm{C}$ e $32^{\circ} \mathrm{C}$ e abaixo de $16^{\circ} \mathrm{C}$ e acima de $36^{\circ} \mathrm{C}$ são letais para a espécie. De acordo com os mesmos autores a espécie tolera os limites de salinidade de 
IGARASHI, M.A..

Aspectos do desenvolvimento do cultivo do bijupirá Rachycentron canadum no Brasil e no mundo

4 e 35. Chen et al. (2009) recomendaram a salinidade 30 como ideal para o desenvolvimento de juvenis de bijupirá. A idade máxima é de aproximadamente 15 anos para bijupirá vivendo em águas mais frias e aproximadamente 10 anos para bijupirá que vive em águas quentes (ACE, 2003). Os bijupirás adultos chegam ao comprimento de até $2 \mathrm{~m}$ e peso de $60 \mathrm{~kg}$ (HOLT et al., 2007). Várias pesquisas no Brasil estão sendo realizadas com base nas informações e resultados alcançados no mundo, embora existem vários tipos de restrições no Brasil, como falta de pesquisas, conhecimento incipiente das técnicas de cultivo, inexistência de rações adequadas entre outras.

\section{Reprodução}

Na década de 1970 o cultivo de bijupirá começou em pequena escala em Taiwan (NHU et al., 2011). A primeira reprodução ocorreu em Taiwan em 1994 (LIAO et al., 2001) e a reprodução em massa foi alcançada desde 1997 (LIAO et al., 2004).No Vietnã, a desova de bijupirá pode ser obtida naturalmente ou por injeção hormonal de reprodutores maturos (NHU et al., 2011). EmboraEstrada et al. (2016) relataram que a reprodução em cativeiro é relativamente fácil porque a maturidade ocorre frequentemente dentro de 2 anos de cultivo. 0 peso corporal dos reprodutores podem variar de 15 a 25 kg (NHU et al., 2011).

Hamilton et al. (2013) relataram que os reprodutores são alimentados diariamente, geralmente com alimentos de origem marinha frescos ou congelados, como peixes (sardinha e cavalinha), lulas e camarões. Na área da Baía de Chesapeake, Richards (1967) relatou que a fecundidade variou de 1,9 a 5,4 milhões de ovos para seis cobia. Rodrigues (2018) relatou que para a desova, os reprodutores de cobia são estocados e criados em viveiros ou tanques com coletores de ovos. De acordo com o mesmo autor os ovos fertilizados podem ser colocados em tanques berçários ou viveiros, onde eclodem. Ovos fertilizados eclodem dentro de 21 - $37 \mathrm{~h}$ com a temperatura da água de $31-22{ }^{\circ} \mathrm{C}$ (ESTRADA et al., 2016). Após os estágios de crescimento posteriores em tanques ou viveiros, o crescimento dos juvenis ocorre em tanques ou gaiolas próximas da costa, antes que os peixes sejam transferidos para gaiolas em mar aberto para a engorda final (FAO, 2017).

\section{Produção de larvas e formas jovens}

Nos poucos laboratórios nacionais que trabalham com $R$. canadum, a criação de larvas é realizada intensivamente sob condições controladas com o uso de sistemas de manejo de água semiestáticos (COSTA, 2015). No Vietnã, podem existir duas tecnologias de criação para larvicultura de bijupirá: intensiva e semi-intensiva (NHU et al., 2011): o cultivo intensivo pode ser conduzida em sistemas de recirculação de aquicultura utilizando alimentos vivos produzidos e a tecnologia semiintensiva pode ser implementado em viveiros ao ar livre usando zooplâncton parcialmente naturale é realizado principalmente nas maiores instalações de RIA-1 localizadas na província de Haiphong e nos incubatórios privados localizados na província de Khanh-hoa. Estrada et al. (2016) relataram que a pós-larva pode ser produzido em massa em viveiros a um custo relativamente baixo. Os mesmos autores relataram que nos últimos anos, sistemas de recirculação intensivo e superintensivo para 
IGARASHI, M.A..

Aspectos do desenvolvimento do cultivo do bijupirá Rachycentron canadum no Brasil e no mundo

berçário (de 2 para 100 - $150 \mathrm{~g}$ ) foram desenvolvidos com taxas de sobrevivência de mais de $90 \%$. Segundo Carvalho (2005) após a eclosão, as larvas podem medir de 1,8 a 2,7 mm, no seu comprimento total. Os indivíduos iniciam a alimentação aos 3 dias de vida após a eclosão e são cultivadas até $20^{\circ}$ dia com sobrevivência de 5-10\% (LIAO et al., 2004). A densidade nos estágios iniciais em sistema de tanques pode ser de 2 indivíduos/litro (FAO, 2008), com um individuo/litro foram obtidos melhores resultados nas pesquisas (HOLT et al., 2007). Durante estas fases, o alimento fornecido pode ser preferencialmente copépodos (SHAFFER; NAKAMURA, 1989). Os rotíferos enriquecidos podem ser fornecidos inicialmente na densidade de 3 a 5 /ml (KAISER; HOLT, 2005).

Nos estágios finais de larvas e juvenis recentes de bijupirá podem ser adotados os procedimentos de desmame (BENETTI, 2002). O desmame de póslarva a partir de 20 dias em diante para alimentos peletizados é viável (ESTRADA et al., 2016). Porém para o desenvolvimento satisfatório das larvas, a qualidade da água do cultivo deve estar dentro dos parâmetros físicoquímicos desejados. As larvas podem ser cultivadas em águas verdes com $12 \times 104$ células $/ \mathrm{ml}$ de Nannochloropsis oculata, sendo que outras espécies de microalgas como Isochrysis galbana, ou Tetraselmis sp. podem ser utilizadas (CARVALHO, 2005). De acordo com Cavalli e Hamilton (2007) até a presente data no Brasil, a larviculturas em grande escala ainda não obtiveram o sucesso alcançados em outros países.

Assim é necessário incrementar as investigações sobre a produção de bijupirá através da larvicultura comercial. São necessários também pesquisas sobre doenças e elaboração de ração artificial. Dietas adequadas às necessidades nutritivas e o crescimento desta espécie demonstram que os indivíduos podem ser desenvolvidos com sucesso em sistemas comuns de cultivo, já que eles se adaptam bem às condições de confinamento e ao alimento utilizado. 0 sistema de cultivo pode ser relativamente simples, quando comparado com a metodologia utilizada para várias espécies de peixes marinhos cultivados.

\section{Engorda}

Os peixes (bijupirá) podem ser estocados com tamanho e peso, respectivamente de 9 a13 $\mathrm{cm}$ e 2 a 3 g na densidade de cerca de 20.000 peixes em tanques do tipo "circulo polar" com 40 ou $50 \mathrm{~m}$ de diâmetro $(0,5$ peixes/m3) (ACE, 2003) e são despescados com uma produção de cerca de 14 $\mathrm{kg} / \mathrm{m} 3$ (KAISER; HOLT, 2005). Se os regimes de alimentação e temperatura forem ótimos, o surpreendente crescimento de $30 \mathrm{~g}$ (alevinos com 55-70 dias de idade) para 6-10kg deve ser atingido em 280-390 dias (SU et al., 2000). O bijupirá cresce de 2 a 3 g a 6 kg com uma conversão alimentar de 1,3 (ACE, 2003), 1,5 (SOUZA, 2007) ou pode variar de 1,5 a 1,8 (PAN, 2005). No entanto avaliando diferentes temperaturas $\left(23\right.$ a $\left.35^{\circ} \mathrm{C}\right)$ sobre o desempenho e dinâmica bioenergética de juvenis de bijupirá em diferentes faixas de peso $(10 \mathrm{a} 200 \mathrm{~g})$, verificaram que os peixes de peso entre 70 e $200 \mathrm{~g}$ apresentam maior consumo e melhor eficiência alimentar nas faixas de temperaturas compreendidas entre 27 e $33^{\circ} \mathrm{C}$ (SUN; CHEN, 2014). Salinidade acima de 25 ppt é essencial para o crescimento ideal de Cobia (VIKASPEDIA, 2006). 
IGARASHI, M.A..

Aspectos do desenvolvimento do cultivo do bijupirá Rachycentron canadum no Brasil e no mundo

O cultivo de bijupirá em gaiola foi iniciada em Taiwan no início dos anos 90, onde cerca de $80 \%$ das gaiolas marinhas foram dedicadas ao cultivo de bijupirá (LIAO et al., 2004). Várias investigações foram realizadas sobre a tecnologia de larvicultura e cultivo engorda de bijupirá em gaiolas marinhas (HOLT et al., 2007; BENETTI et al., 2008; GOPAKUMAR et al., 2011). Em ambientes com maior energia, como no mar aberto, gaiolas flutuantes (Figura 2), de formato circular, fabricadas em polietileno de alta densidade, são geralmente utilizadas (HAMILTON et al., 2013).

Figura 2. Layout de gaiola marinha de polietileno de alta densidade (HDPE) - Frame e gaiolas de rede (inner \& outer) (VIKASPEDIA, 2006).

A presa natural do bijupirá inclui peixes, crustáceos e moluscos (ARENDT et al., 2001). De acordo com Pan (2005) em Taiwan durante o período de cultivo são ofertados 2 tipos de alimento: ração comercial úmida peletizada para peixes marinhos $(45,3 \%$ de proteína bruta, $16 \%$ de concentração lipídica e $11,0 \%$ de cinzas) e segundo Nguyen et al. (2008) e Nhu et al. (2011) subprodutos a partir de rejeitos e descartes da indústria pesqueira são utilizados pelo baixo valor comercial. Para os bijupirás maiores que $1 \mathrm{~m}$ a dieta pode consistir de até $80 \%$ de pescado (ACE, 2003).

Bezerra et al. (2016) relataram que em sistemas de produção industrial (IS) e familiar (FS) para o cultivo de bijupirá ( $R$. canadum) em gaiolas flutuantes no Brasil foram utilizadas ração extrusada, que afundam-se lentamente com $45 \%$ de proteína, 8 \% de lipídeos no alimento (Tabela 1). No Brasil são necessários para o sucesso de um cultivo comercial incrementar as pesquisas, com o objetivo de determinar e conhecer melhor o desenvolvimento, o comportamento alimentar, requerimentos nutricionais, formulação de uma dieta e que possua aceitabilidade pelos bijupirás. Embora os sistemas de produção industrial (IS) e familiar (FS) para o cultivo de bijupirá ( $R$. canadum) em gaiolas flutuantes no Brasil (Tabela 1) estão sendo desenvolvidos.

Tabela 1. Característica dos sistemas de produção industrial (IS) e familiar (FS) para o cultivo de bijupirá ( $R$. canadum) em gaiolas flutuantes no Brasil. IS FS Número, tipo e tamanho das gaiolas 24 HDPE gaiolas flutuantes circulares com $1607 \mathrm{~m} 36$ gaiolas flutuantes de madeira quadrada com 75 m3 Tamanho inicial do peixe Engorda: 15 - 20 g Berçário: 2 g Engorda: 15 - 20 g Densidade de estocagem 3,0 peixes m-3 3,0 peixes m-3 Período do ciclo de cultivo Engorda: 12 meses Berçário: 2 meses Engorda: 12 meses

\begin{tabular}{|c|c|c|}
\hline $\begin{array}{c}\text { Número, tipo e } \\
\text { tamanho das gaiolas }\end{array}$ & $\begin{array}{l}24 \text { HDPE gaiolas flutuantes } \\
\text { circulares com } 1607 \mathrm{~m}^{3}\end{array}$ & $\begin{array}{c}6 \text { gaiolas flutuantes madeira } \\
\text { quadrada com } 75 \mathrm{~m}^{3}\end{array}$ \\
\hline $\begin{array}{l}\text { Tamanho inicial do } \\
\text { peixe }\end{array}$ & Engorda: $15-20 \mathrm{~g}$ & Berçário: $2 \mathrm{~g}$ Engorda: 15 - $20 \mathrm{~g}$ \\
\hline $\begin{array}{l}\text { Densidade de } \\
\text { estocagem }\end{array}$ & 3,0 peixes $\mathrm{m}^{3}$ & 3,0 peixes $\mathrm{m}^{3}$ \\
\hline $\begin{array}{l}\text { Período do ciclo de } \\
\text { cultivo }\end{array}$ & Engorda: 12 meses & $\begin{array}{l}\text { Berçário: } 2 \text { meses } \\
\text { Engorda: } 12 \text { meses }\end{array}$ \\
\hline Número de alevinos & 115.704 & 1.350 \\
\hline
\end{tabular}


IGARASHI, M.A..

Aspectos do desenvolvimento do cultivo do bijupirá Rachycentron canadum no Brasil e no mundo

\begin{tabular}{|c|c|c|}
\hline por ciclo & & \\
\hline Alimentação & $\begin{array}{c}\text { Extrusado, afundam-se lentamente } \\
45 \% \text { de proteína, 8\% de lipídeos no } \\
\text { alimento com duas refeições diárias }\end{array}$ & $\begin{array}{c}\text { Extrusado, afundam-se lentamente } \\
45 \% \text { de proteína, 8 \% de lipídeos no } \\
\text { alimento com 4 (berçário) ou 2 } \\
\text { (engorda) refeições diárias }\end{array}$ \\
\hline $\begin{array}{c}\text { Trabalhadores } \\
\text { contratados }\end{array}$ & 17 & Nenhum (familiar) \\
\hline Preço de venda & US $\$ 8,62 \mathrm{~kg}^{-1}$ & US $\$ 8,62 \mathrm{~kg}-1$ \\
\hline
\end{tabular}

Fonte: Bezerra et al. (2016)

Os valores do quilograma do bijupirá podem variar conforme o seu tamanho e o preço do mercado. Conforme a Tabela 1, o preço de venda dos peixes produzidos em sistemas de produção industrial (IS) e familiar (FS) para o cultivo de bijupirá ( $R$. canadum) em gaiolas flutuantes no Brasil o valor pode alcançar US\$ 8,62 kg-1 (BEZERRA et al., 2016). Collaço et al. (2015) relataram sobre a ferramenta SIG demonstrou contribuir de forma efetiva, facilitando a tomada de decisão por parte de maricultores e gestores e, se utilizada antes da tentativa da implantação de um Sistema de Informações Geográficas, baseado em banco de dados estruturado, conforme o que foi elaborado em seu estudo representa um avanço metodológico e uma ferramenta de gestão imprescindível em avaliação de viabilidade da maricultura.

De acordo com os mesmos autores, portanto, pode-se utilizar técnicas de geoprocessamento para indicar áreas propícias ao cultivo de Bijupirá Rachycentron canadum na região estuarinalagunar de Cananéia, Estado de São Paulo, Brasil, considerando variáveis físicas, químicas, biológicas do ambiente costeiro e estuarino, e o metabolismo da espécie. Porém o presente artigo de revisão pode demonstrar que o desempenho no crescimento do bijupirá pode ser incrementada com desenvolvimento de um manejo correto na qualidade da água apesar de relativamente uma ampla tolerância ao ambiente e na escolha de alimentos de baixo custo e eficientes utilizados na engorda de bijupirá. As pesquisas com juvenis relatam que as suas necessidades nutritivas e o seu crescimento podem ser apropriados para a engorda no Brasil.

Embora a engorda de bijupirá em sistema intensivo demonstra faturamento satisfatório, ainda é necessário melhoria, aprimoramento e deve ser lembrado, que não existem ainda empreendimentos para engorda para sua produção comercial em grande escala no Brasil, e os custos reais para implantação do cultivo e a quantidade de bijupirá engordados estão ainda em fase de pesquisa no Brasil. Atualmente, a enfermidade não é apontado como o maior entrave, mas este fato pode alterar quando os bijupirás forem criados em grande escala de forma comercialmente viável em cativeiro no Brasil. Portanto é primordial conservar as condições da qualidade da água dentro dos padrões de uma alta qualidade ambiental para a criação. Chu et al. (2013) relataram que o bijupirá, assim como outras espécies criadas através da aquicultura, são vulneráveis a doenças infecciosas que podem ser parasitárias, bacterianas ou virais.

De acordo com os mesmos autores as doenças parasitárias, que causaram perdas econômicas em peixes em cativeiro, são particularmente comuns devido a infestações por ectoparasitas e as 
IGARASHI, M.A..

Aspectos do desenvolvimento do cultivo do bijupirá Rachycentron canadum no Brasil e no mundo

infestações ectoparasitárias mais frequentemente relatadas no bijupirá cultivada incluem parasitas crustáceos, vermes da pele, mixosporídeos e protozoários. Chiau et al. (2004) observaram que Streptococcus spp. e infestações monogêneas da pele do bijupirá levaram à cegueira. De acordo com os mesmos autores os parasitas mixosporídeos também têm sido associados à mortalidade em massa no bijupirá cultivado. 0 parasita Amyloodinium em poucos dias pode provocar a morte de juvenis de bijupirás e caso não houver um tratamento (KAISER; HOLT, 2005). De acordo com Cavalin (2005), ou é observado que em todos estágios de sua vida e quando infectados com este parasita, sulfato de cobre pentahidratado $\left(\mathrm{CuSO}_{4}\right)$ pode ser utilizado no controle da eclosão dos cistos do parasita, administrado a 0,5 ppm em um período desete dias na água do cultivo de bijupirá. Estudos têm relatado recentemente um aumento do número de surtos de doenças bacterianas ao longo do ciclo de cultivo do bijupirá. Vibriose, micobacteriose, furunculose e estreptococose são as doenças bacterianas mais comuns relatadas (LIAO et al. 2004).

As doenças virais também causam muitas vezes grandes perdas e reduções na produção de espécies de peixes aquícolas (MUNDAY et al. 2002). Pan (2005) relatou que em Taiwan na etapa de engorda a mortalidade dos bijupirás ocorre principalmente devidos as temperaturas baixas e os ectoparasitas Neobenedenia girellae e Caligus sp. De acordo com o mesmo autor no tratamento contra uma infestação de ectoparasitas Neobenedenia e Caligulus, os bijupirás serão introduzidos em água doce contendo antibiótico (oxitetraciclina) por cinco minutos. Porém, o presente artigo de revisão pode demonstrar que os bijupirás criados em uma água de boa qualidade, densidade ideal, e uma dieta adequada poderá ter uma diminuição na ocorrência ou dificilmente estarão sujeitas a enfermidades. Mais investigações no sentido de conhecer mais sobre enfermidades em bijupirá, seus meios de contágio ou tratamentos efetivos são necessários.

\section{Material e métodos}

Este trabalho é uma pesquisa descritiva utilizando materiais bibliográficos publicados entre 1884 e 2019, relacionados aos aspectos do desenvolvimento do cultivo do bijupirá $R$. canadum no Brasil e no mundo. Nesse contexto o levantamento da presente revisão bibliográfica relata principalmente a espécie, reprodução, produção de larvas, formas jovens e engorda.

\section{Resultados e discussão}

Nesse levantamento foram acessados aproximadamente 80 e citados 64 documentos. Os resultados das pesquisas obtidas no presente artigo de revisão, o bijupirá demonstra perspectiva para o cultivo comercial, embora a espécie apresente importância biológica, ecológica e econômica obtendo assim progressos no desenvolvimento de uma tecnologia comercial. 
IGARASHI, M.A..

Aspectos do desenvolvimento do cultivo do bijupirá Rachycentron canadum no Brasil e no mundo

As pesquisas demonstram que pode ser possível cultivar o bijupirá em cativeiro no Brasil e com o surgimento de novas tecnologias, poderá melhorar no futuro a qualidade de vida dos criadores, gerando emprego e renda, através da comercialização de bijupirá que atenda às necessidades dos mercados domésticos e de exportação, resultando, dessa maneira, um intercâmbio mais favorável para a economia do país. Pesquisas no Brasil estão sendo realizadas com base nas informações e resultados alcançados no mundo, embora existem vários tipos de restrições no Brasil, como falta de pesquisas, conhecimento incipiente das técnicas de cultivo, inexistência de rações adequadas entre outras. Mais especificamente entre as limitações para o desenvolvimento do cultivo comercial de bijupirá podem ser consideradas a carência de uma produção de pós-larvas de bijupirá em grande escala, demora e dificuldades nas questões legais para implantação e funcionamento do cultivo, falta de materiais e técnicos em todas as etapas do cultivo e desenvolvimento de dietas adequadas para o cultivo de bijupirá.

O cultivo de bijupirá apresenta potencial para o seu cultivo no Brasil. Apresenta uma boa taxa de crescimento, alcançando o tamanho comercial em um período adequado, a qualidade organoléptica da carne, e o ganho de peso do animal com uma boa conversão alimentar são características desejáveis para uma espécie candidata a piscicultura marinha.

\section{Considerações finais}

De acordo com o que foi relatado anteriormente, pode haver viabilidade econômica para o desenvolvimento do cultivo do bijupirá R. canadum no Brasil mesmo apresentando limitações de ordem técnica, econômicas e na formação de pessoal técnico especializado. Devem ser intensificados os esforços nas pesquisas com adequadas técnicas de manejo para os pequenos produtores, de forma a aumentar a sua eficiência, destacando o seu sabor agradável ao paladar, a qual constitui alternativa viável de alimento face ao esgotamento dos estoques naturais de pescado. Superando as limitações citadas anteriormente poderemos ter no futuro o cultivo sustentável de bijupirá em grande escala.

\section{Agradecimentos}

Agradecemos ao Professor Yoshiaki Deguchi (Nihon University-Japão) “in memorian” pelas importantes informações fornecidas sobre a aquicultura.

\section{Referências}

ACE. Cobia (Rachycentron canadum) Aquaculture, 2003. Disponível em: h ttp://w ww. ace4all. com / live200611/ docs/ Cobia.pdf >. Acesso em: 25 jul. 2007. 
IGARASHI, M.A..

Aspectos do desenvolvimento do cultivo do bijupirá Rachycentron canadum no Brasil e no mundo

ARENDT, M. D.; OLNEY, J. E.; LUCY, J. A. 2001. Stomach content analysis of cobia, Rachycentron canadum, from lower Chesapeake Bay. Fisheries Bulletin, Washington, v. 99, n. 4, p. 665-670, 2001.

ARGENTIM, D. Automação do manejo alimentar de bijupirá Rachycentron canadum. Botucatu, 2016, 63 f. Tese (Doutorado) - Universidade Estadual Paulista, Faculdade de Medicina Veterinária e Zootecnia, Botucatu, 2016. Disponível em < https://repositorio.unesp.br/bitstream/handle/11449/132891/argentim_d_dr_bot_int.pdf;jsessionid= ECBBC7F9957A00975C5A906DFF6CCF25?sequence=3> Acesso em 12 de novembro de 2018.

BENETTI, D.D. AND M.R. ORHUN. Aquaculture of pelagic fish: IV. Cobia (Rachycentron canadum). Global Aquaculture Alliance Advocate, St Louis, v. 5, n. 4, p. 61-62, 2002.

BenetTI, D. D., ORHUN, M. R., SARDEnBerg, B., O'HANLON, B., WELCH, A., HOENIG, R., ZINK, I., RIVERA, J. A., DENLINGER, B., BACOAT, D., PALMER, K. AND CAVALIN, F. Advances in hatchery and growout technology of cobia Rachycentron canadum (Linnaeus). Aquaculture Research, Chichester, v. 39, n. 7, p. 701-711, 2008.

BENETTI D. D.; O'HANLON, B.; RIVERA, J. A.; WELCH, A. W.; MAXEY, C.; ORHUN, M. R. Growth rates of cobia (Rachycentron canadum) cultured in open ocean submerged cages in the Caribbean. Aquaculture, Amsterdam, v. 302, n. 34, p. 195-201, 2010.

BEZERRA, T. R. Q.; DOMINGUES, E. C.; MAIA FILHO, L. F. A.; ROMBENSO, A. N.; HAMILTON, S.; CAVALLI, R. O. Economic analysis of cobia (Rachycentron canadum) cage culture in large- and small-scale production systems in Brazil. Aquaculture International, Dordrecht, 2016, v. 24, Issue 2, p. 609-622. DOI: 10.1007/s10499-015-9951-2 Disponível em < http://agris.fao.org/agrissearch/search.do?recordID=US201700096127 > Acesso em 12 de novembro de 2018.

BEZERRA, T. R. Q.; DOMINGUES, E. C.; MAIA FILHO, L. F. A.; ROMBENSO, A. N.; HAMILTON, S.; CAVALI, R. O. Economic analysis of cobia (Rachycentron canadum) cage culture in large - and small - scale production systems in Brazil. Aquaculture International, Dordrecht, v. 24, p. 609 - 622, 2016.

BOTELHO, M. T. Biomarcadores na avaliação do estado fisiológico de juvenis de beijupirás, Rachycentron canadum (Linnaeus, 1766), de cultivo. 2017, 115 f. Dissertação (Mestrado em Ciências, Programa de Oceanografia, área de concentração Oceanografia Biológica) Instituto Oceanográfico de São Paulo, São Paulo. Disponível em:

file:///C:/Users/marco.igarashi/Downloads/Dissertacao_Botelho_Marina_Corrigida.pdf>Acesso em 14 de dezembro de 2018.

CALIXTO, F. A. A.; DINIZ, J. B.; MACHADO, E. S.; FELIZARDO, S. C. SÃO CLEMENTE, E. F. M.; MESQUITA, N. N. Primeiro relato de Hysterothylacium deardorffoverstreetorum (Raphidascarididae) em bijupirá de criação, Rachycentron canadum (Linnaeus 1766), no Brasil. Arquivo Brasileiro de Medicina Veterinária e Zootecnia, Belo Horizonte, v. 69, n.1, p. 85-88, 2017. Disponível em < 
IGARASHI, M.A..

Aspectos do desenvolvimento do cultivo do bijupirá Rachycentron canadum no Brasil e no mundo

http://www.scielo.br/pdf/abmvz/v69n1/0102-0935-abmvz-69-0100085.pdf> Acesso em 12 de novembro de 2018.

CARVALHO, M. B. Larvicultura de Bijupirá. 2005. Disponível em: Acesso em: 4 maio 2006. CARVALHO, M. B. Larvicultura de Bijupirá. 2005. Disponível em< https://panoramadaaquicultura.com.br/larviculturade-bijupira/> Acesso em: 4 maio 2006.

CASTELLANOS-GALINDO, G. A.; BAOS, R.; ZAPATA, L. A. Mariculture-induced introduction of cobia Rachycentron canadum (Linnaeus, 1766), a large predatory fish, in the Tropical Eastern Pacific. Biolnvasions Records, Waltham, v. 5, Issue 1: 55-58, 2016. Disponível em < https://www.researchgate.net/publication/293653086_Maricultureinduced_introduction_of_cobia_Rachy centron_canadum_Linnaeus_1766_a_large_predatory_fish_i n_the_Tropical_Eastern_Pacific $>$ Acesso em 12 de novembro de 2018.

CAVALIN, F. G. Bijupira, Um sistema de maturação de bijupirá (Rachycentron canadum). 2005. Disponível em: <h ttp://w ww.panoramadaaquicultura. com.br/ paginas/ Revistas/ 91/ Bijupira91. asp>. Acesso em: 4 mai 2006.

CAVALLI, R.O.; HAMILTON, S. A. 2007. Piscicultura marinha no Brasil. Afinal, quais as espécies boas para cultivar? Panorama da Aquicultura, Rio de Janeiro, v.17, n. 104, p. 50-55, 2007.

CAVALLI, R. O.; DOMINGUES, E. C.; HAMILTON, S. Desenvolvimento da produção de peixes em mar aberto no Brasil: possiblidades e desafios. Revista Brasileira de Zootecnica. Viçosa, v. 40, p. 155 - 164, 2011.

CAVALLI, R. O. Com excelentes condições ambientais, piscicultura marinha carece de investimentos. Visão Agrícola, Piracicaba, n. 11, p. 18 - 23, 2012.

CHEN, G. Z.; WANG, Z. W.; GU, B. Effects of salinity on growth and energy budget of juvenile cobia Rachycentron canadum. Journal World Aquaculture Society,Baton Rouge, v. 40, n. 3, p. 374- 382, 2009.

CHU, K. B.; ABDULAH, A.; ABDULlaH, S. Z.; BAKAR, R. A. A Case Study on the Mortality of Cobia (Rachycentron canadum) Cultured in Traditional Cages. Tropical Life Science Research, Penang, 2013; v. 24, n. 2, p. 77-84, 2013.Disponível em < https://www.ncbi.nlm.nih.gov/pmc/articles/PMC3935374/ > Acesso em 17 de dezembro de 2018.

CHIAU, W.Y.; CHOU, C. L.; SHIH, Y. C. Marine aquaculture in Chinese Taipei: Status, institutions and challenges. APEC Bulletin on Marine Resource Conservation and Fisheries. v. 6, n. 2, p.15-20, 2004.

COLLAÇO, F. L.; SARTOR, S. M.; BARBIERI, E. Cultivo de Bijupirá (Rachycentron canadum) em Cananeia, SP, Brasil: Avaliação da viabilidade utilizando geoprocessamento. Revista de Gestão Costeira Integrada, Portugal.2015, vol.15, n.2, p.277-289. 
IGARASHI, M.A..

Aspectos do desenvolvimento do cultivo do bijupirá Rachycentron canadum no Brasil e no mundo

COLLETTE, B. B. Rachycentridae. The Living Marine Resources of the Western Central Pacific. In: Carpenter KE, Niem VH (Eds.), Bony Fishes Part 2 (Mugilidae to Carangidae), v. 4, 1999. FAO, Rome, Italy.

COSTA, G. W. W. F. Mapeamento cromossômico de DNAs repetitivos com fins biotecnológicos em peixes marinhos de interesse comercial - Rachycentridae e Lutjanidae. 2015, $144 \mathrm{f}$. Tese apresentada ao programa de pós-graduação em Biotecnologia - Rede Nordeste de Biotecnologia (RENORBIO) como parte dos pré-requisitos obrigatórios para obtenção do título de Doutor em Biotecnologia. UFRN, Natal-RN. Disponível em < https://repositorio.ufrn.br/jspui/handle/123456789/20109> Acesso em 12 de novembro de 2018.

DOMINGUES, E. C.; HAMILTON, S.; BEZERRA, T. R. Q.; CAVALLI, R. O. Viabilidade econômica da criação do beijupirá em mar aberto em Pernambuco. Boletim do Instituto de Pesca, São Paulo, v. 40, n. 2 , p. 237 249, 2014. Disponível em < https://www.pesca.sp.gov.br/40_2237-249.pdf > Acesso em 12 de novembro de 2018.

DOMINGUES, E. C. Cultivo de Beijupirá (Rachycentron canadum): análise da viabilidade econômica. 78 p. 2012. Dissertação Mestrado em Recursos Pesqueiros e Aquicultura). Departamento de Pesca e Aquicultura. UFRPE. $\quad$ Recife. Disponível em http: //www.tede2.ufrpe.br:8080/tede/bitstream/tede2/6297/2/Ernesto\%20de\%20Carvalho\%20Domi ngues.pdf> Acesso em 12 de novembro de 2018.

ESTRADA, U. R.; YASUMARU, F. A.; TACONA, A. G. J.; LEMOSA, D. Cobia (Rachycentron canadum): A Selected Annotated Bibliography on Aquaculture, General Biology and Fisheries 1967 - 2015. Reviews In Fisheries Science \& Aquaculture, United States, 2016, v. 24, n. 1, 1 - 97. Disponível em <https://www.tandfonline.com/doi/abs/10.1080/23308249.2015.1088821 > Acesso em 12 de novembro de 2018.

FAGUNDES, G. A.; ROCHA, M.; SALAS-MELLADO, M. M. Improvement of protein content and effect on technological properties of wheat bread with the addition by cobia (Rachycentron canadum). Food Research, Toronto, v. 2, n. 3, p. $221 \quad$ - 227, 2018. Disponível em < http: //www.myfoodresearch.com/uploads/8/4/8/5/84855864/_2_fr-2017275_fagundes_2.pdf>Acersso em 18 de dezembro de 2018.

FAO - Food and Agriculture Organization. Cultured aquatic species information programme. Rachyceniron canadum. Text by J. B. Kaiser, J. G. Holt. In: FAO Fisheries and Aquaculture Department. Rome, 2007. Disponível em <

http://www.fao.org/fishery/culturedspecies/Rachycentron_canadum/en> Acesso em 13 de dezembro de 2018.

FAO. 2013. Cultured Aquatic Species Information Programme - Rachycentron canadum. Disponível em: <www.fao.org/fishery/culturedspecies/ Rachycentroncanadum/en>Acesso em: 29 jan. 2013. 
IGARASHI, M.A..

Aspectos do desenvolvimento do cultivo do bijupirá Rachycentron canadum no Brasil e no mundo

FAO, 2017. Cultured aquatic species information program: Rachycentron canadum (Linnaeus, 1766). Rome, Italy: Food and Agriculture Organization of the United Nations. Disponível em < http://www.fao.org/fishery/culturedspecies/Rachycentron_canadum/en> Acesso em 17 de dezembro de 2018.

FAO, 2018. Fishery and aquaculture statistics: aquaculture production (2016). Rome, Italy: FAO, vii +244 p. Disponível em

http: //www.fao.org/fishery/static/Yearbook/YB2016_USBcard/root/aquaculture/yearbook_aquacult ure.pdf > Acesso em 17 de dezembro de 2018.

GOODE, G.B. The fisheries and fishery industries of the United States. Section 1: Natural history of useful aquatic animals. Washington D.C: Text. U.S. Commission on Fisheries, 1884, 895 p.

GOPAKUMAR, G.; ABDUL NAZAR, A. K.; TAMILMANI, G.; SAKTIVEL, M.; KALIDAS, C.; RAMAMOORTHY, N.; PALANICHAMY, S.; ASHOK MAHARSHI, V.; SRINIVASA RAO, K.; SYDA RAO, G. Broodstock development and controlled breeding of cobia Rachycentron canadum (Linnaeus 1766) from Indian seas. Indian Journal of Fisheries, Cochin, v. 58, n. 4, p. 27-32, 2011.

HARDY, J.D., Jr. Development of fishes of the Mid-Atlantic Bight: An atlas ofegg, larval and juvenile stages. Vol. III. Aphredoderidae through Rachycentridae. U. S. Fish Wild. Serv., Biology Service Program, FWS/OBS-78/12, 1978, 394 p.

HAMILTON, S.; SEVERI, W.; CAVALLI, R. O. Biologia e aquicultura do beijupirá: uma revisão. Boletim do Instituto de Pesca, São Paulo, v. 39, n. 4, p. 461 - 477, 2013. Disponível em < https://www.pesca.sp.gov.br/39_4_461-477.pdf> Acesso em 12 de novembro de 2018.

HARLIOGLU, M. M.; FARHADI, A. Iranian fisheries status: an update (2004-2014). Fisheries and aquaculture journal, USA, v. 8, n.1, p. 1 - 8, 2017. Disponível em < https://www.omicsonline.org/openaccess/iranian-fisheries-status-an-update-20042014-2150-35081000192.php?aid=86858> Acesso em 17 de dezembro de 2018.

HOLT, G. J.; FAULK, C. K.; SCHWARZ, M. H. A review of the larviculture of cobia, Rachycentron canadum, a warm water marine fish. Aquaculture, Amsterdam, 268: 181-187, 2007.

HUANG C. T., MIAO SHA, NAN FANHUA, JUNG SHIMU. Study on regional production and economy of cobia Rachycentron canadum commercial cage culture. Aquaculture International, Dordrecht. v.19, n. 4, p. 649-664, 2011. Disponível em < https://www.cabi.org/ISC/abstract/20113286033> Acesso em 17 de dezembro de 2018.

KAISER, J. B.; HOLT, G. J. Cobia: A new species for aquaculture in the US. World Aquaculture, Baton Rouge, v. 35, n. 2, p. 12-14. 2004. 
IGARASHI, M.A..

Aspectos do desenvolvimento do cultivo do bijupirá Rachycentron canadum no Brasil e no mundo

KAISER, J. B.; HOLT, G. J. Species Profile, Cobia. SRAC (Southern Regional Aquaculture Center, USA) Publication n. 7202. August 2005. 6 p.

KWOK, R. Fish escapes from marine farms raise concerns about wildlife. Science News, Washington. 190:22, 2016. Disponível em < https://www.sciencenews.org/article/fish-escapesmarine-farms-raiseconcerns-about-wildlife > Acesso em 17 de dezembro de 2018.

LIAO, I. C., SU, H. M., CHANG, E. Y. Techniques in finfish larviculture in Taiwan. Aquaculture, Amsterdam, 200, 1-31, 2001.

LIAO, I. C.; HUANG, T. S.; TSAI, W. S.; HSUEH, C. M.; CHANG, S. L.; LEANO, E. M. Cobia culture in Taiwan: current status and problems. Aquaculture, Amsterdam, v. 237, n. 1-4, p. 155- 165, 2004.

LIMA, L. N. S.; HAMILTON, S.; BEZERRA, T. R. Q.; CAVALLI, R. O. Identification of áreas with adequate temperature for the culture of cobia in cages along the Brazilian ciast. Revista Brasileira de Ciências Agrárias, Recife. v. 13, n. 3, e5547 2018.

MIAO, S.; JEN, C.C.; HUANG, C.T.; HU, S.H. Ecological and economic analysis for cobia Rachycentron canadum commercial Cage culture in Taiwan. Aquaculture International, Dordrecht, v. 17, n. 2, p. 125141, 2009.

MUNDAY, B. L.; KWANG, J.; MOODY, N. Betanodavirus infections of teleost fish: A review. Journal of Fish Diseases, Oxford, v. 25, n. 3, p. 127-142, 2002.

NHU, V. C.; NGUYEN, H. Q.; LE, T. L.; TRAN, M. T.; SORGELOOS, P.; DIERCKENS, K.; REINERTSEN, H.; KJØRSVIK, E.; SVENNEVIG, N. Cobia Rachycentron canadum aquaculture in Vietnam: Recent developments and prospects. Aquaculture, Amsterdam, v. 315, n. 1-2, p. 20- 25, 2011.

NGUYEN, Q.H.; SVEIER, H.; BUI, V.H.; LE, A.T.; NHU, V.C.; TRAN, M.T.; SVENNEVIG, N. 2008 Growth performance of cobia, Rachycentron canadum, in sea cages using extruded fish feed or trash fish. In: YANG, Y.; VU, X.Z.; ZHOU, Y.Q. Cage aquaculture in Asia: Proceeding of the second international symposium on cage aquaculture in Asia. Manila, Philippines: Asian Fishery Society. p.42-47.

PAN, J. Um jeito taiwanês de criar bijupirá. Panorama da Aquicultura, Rio de Janeiro, v. 15, n. 90 , p. 36 39, 2005.

PHILIPOSE, K. K.; JAYASREE LOKA, SHARMA, S. R. K.; DIVU, D., RAO, K. S.; NARASIMHULU SADHU, PRAVEEN DUBE, GOPAKUMAR, G.; RAO, G. S. Farming of cobia, Rachycentron canadum (Linnaeus 1766) in open sea floating cages in India. Indian Journal of Fisheries, v. 60, n. 4, p.35-40, 2013. Disponível em <https://www.cabi.org/ISC/abstract/20143139838 > Acesso em 17 de dezembro de 2018.

RESLEY, M.; WEBB. K.; HOLT. J. Growth and survival of juvenile cobia, Rachycentron canadum, at different salinities in a recirculating aquaculture system. Aquaculture, Amsterdam, v. 253, n. 1-4, p. 398407, 2006. 
IGARASHI, M.A..

Aspectos do desenvolvimento do cultivo do bijupirá Rachycentron canadum no Brasil e no mundo

RICHARDS, C. E. Age, growth, and fecundity of the cobia, Rachycentron canadum, from Chesapeake Bay and adjacent mid-Atlantic waters. Transactions of the American Fisheries Society, Philadelphia, v. 96, n. 3, p. 343-350, 1967.

RODRIGUES, U. Rachycentron canadum (Cobia) datasheet. Aquaculture Compendium, InvasiveSpecies. CABI (Centre for Agriculture Bioscience International, UK). (PDF) Rachycentron canadum (Cobia) datasheet. Aquaculture Compendium, Invasive Species. CABI (Centre for Agriculture Bioscience International, UK). 2018, $51 \quad$ p. $\quad$ Disponível em < https: / /www.researchgate.net/publication/328102283_Rachycentron_canadum_Cobia_datasheet_A quaculture_Compendium_Invasive_Species_CABI_Centre_for_Agriculture_Bioscience_Internatio nal_UK> Acesso em 17 de dezembro de 2018.

RODRIGUEZ ESTRADA, U.; YASUMARU, F. A.; TACON, A. G. J.; LEMOS, D. Cobia (Rachycentroncanadum): a selected annotated bibliography on aquaculture, general biology and fisheries 1967-2015. Reviews in Fisheries Science \& Aquaculture, Philadelphia. v. 24, n. 1, p. 197, 2016. (/ac/abstract/20163016130). Disponível em <https://www.tandfonline.com/doi/abs/10.1080/23308249.2015.1088821 > Acesso em 17 dse dezembro de 2018.

SAKTHIVEL, M.; ABDUL NAZAR, A. K.; TAMILMANI, G.; KALIDAS, C.; RAMAMOORTHY, N.; ASHOK MAHARSHI, V.; SRINIVASA RAO, K.; GOPAKUMAR, G. Embryonic development of cobia, Rachycentron canadum (Linnaeus, 1766) in controlled conditions. Journal of the Marine Biological Association of India, Cochin, v. 54, n. 2, p. $5-8,2012$.

SANTOS, D. N.; TAKAHASHI, E. H.; VERDE, A. B.; OLIVEIRA, A. L. Supercritical Extraction of Cobia (Rachycentron canadum) Liver Oil as a New Source of Squalene. Food and Public Health, Rosemead, v. 6, n. 6, p. 157-164, 2016.

SHAFFER, R. V.; NAKAMURA, E. L. Synopsis of Biological Data on the Cobia Rachycentron canadum. NOAA Technical Report NMFS 82, FAO Fisheries Synopsis, 153, December 1989, 30 p.

SHIMADA, E. T. Pasteurelose em juvenis de Cobias (Rachycentron canadum) criados em tanques-rede no litoral norte do estado de São Paulo-Brasil. 61 f, 2015. Tese (Doutorado) apresentada ao Programa de PósGraduação em Aquicultura do Centro de Aquicultura da UNESP (CAUNESP), como parte dos requisitos para obtenção do título de DOUTOR em Aquicultura, área de concentração em Patologia de Organismos Aquáticos.

SILVA, C. A. Estudo de mercado do bijupirá Rachycentron canadum em Aracaju, Sergipe. Aracaju: Embrapa Tabuleiros Costeiros, 2016, 23 p. Disponível em <https://www.embrapa.br/busca-depublicacoes/-/publicacao/1065229/estudo-demercado-do-bijupira-rachycentron-canadum-em-aracajusergipe > Acesso em 12 de novembro de 2018. 
IGARASHI, M.A..

Aspectos do desenvolvimento do cultivo do bijupirá Rachycentron canadum no Brasil e no mundo

SOUZA, N. Peixe marinho será produzido em cativeiro. 2007. Disponível em: $<\mathrm{ht}$ tp://ww w.estado. com.br/ suplementos/ agri/ 2007/06/13/agri-1.93. 1.20070613. 54.1. xml>. Acesso em: 13 jun 2007.

SU, M.S.; CHEN, Y. H.; LIAO, I. C. Potential of marine cage aquaculture in Taiwan: Cobia culture. In: I.C. Liao and C.K. Lin (Eds.) Cage Aquaculture in Asia, Asian Fisheries Society, Manila, and World Aquaculture Society, Southeast Asian Chapter, Bangkok, p. 97-106, 2000.

SUN, L., CHEN, H. Effects of water temperature and fish size on growth and bioenergetics of cobia (Rachycentron canadum). Aquaculture, Amsterdam, v. 426-427, p. 172-180, Apr. 2014. Disponível em < https://www.researchgate.net/publication/260340349_Effects_of_water_temperature_and_fish_size _on_growth_and_bioenergetics_of_cobia_Rachycentron_canadum > Acesso em 12 de novembro de 2018.

VIKASPEDIA. Guidelines for Sea Cage Farming in Índia. 2006, 11 p. Disponível em < http://vikaspedia.in/agriculture/fisheries/marine-fisheries/culturefisheries/guidelines-for-sea-cagefarming-in-india > Acesso em 06 de novembro de 2018

ZHOU, Q. C.; WU, Z. H.; TAN, B. P.; CHI, S. Y.; YANG, Q. H. Optimal dietary methionine requirement for juvenile Cobia (Rachycentron canadum). Aquaculture, Amsterdam, v. 258, issue 1-4, p. 551-557, 2006.

YEH, S. P. Cobia culture in Taiwan (Rachycentron canadum). Global Aquaculture Alliance Advocate, Baton Rouge, v. 3, n.2, p. 67-68, 2000. 